\title{
A kinetic mechanism for the thermal decomposition of titanium tetraisopropoxide
}

\author{
Philipp Buerger ${ }^{\mathrm{a}}$, Daniel Nurkowski ${ }^{\mathrm{a}}$, Jethro Akroyd ${ }^{\mathrm{a}, \mathrm{b}}$, Markus Kraft ${ }^{\mathrm{a}, \mathrm{b}, \mathrm{c}, *}$ \\ ${ }^{a}$ Department of Chemical Engineering and Biotechnology, University of Cambridge, \\ New Museums Site, Pembroke Street, Cambridge CB2 3RA, United Kingdom \\ ${ }^{b}$ Cambridge Centre for Carbon Reduction in Chemical Technologies (CARES C4T), \\ \#05-05 CREATE Tower, 1 CREATE Way, Singapore 1386029 \\ ${ }^{c}$ School of Chemical and Biomedical Engineering, Nanyang Technological University, \\ 62 Nanyang Drive, Singapore 637459
}

\section{Abstract}

This work presents the first systematically derived and thermodynamically consistent mechanism to describe the thermal decomposition of titanium tetraisopropoxide (TTIP). The mechanism is based on an analogy between the decomposition of the isopropoxide branches and the decomposition of isopropanol. Flux and sensitivity analyses were used to identify the main reaction pathways in the proposed mechanism as the step-wise release of $\mathrm{C}_{3} \mathrm{H}_{6}$ via four-member ring transition states, the successive abstraction of $\mathrm{CH}_{3}$ radicals via $\mathrm{C}-\mathrm{C}$ bond cleavage followed by hydrogen abstraction to form $\mathrm{C}=\mathrm{C}$ double bonds, and hydrogen abstraction from the isopropoxide methyl groups followed by the release of $\mathrm{C}_{3} \mathrm{H}_{6}$. The final decomposition product was titanium hydroxide, $\operatorname{Ti}(\mathrm{OH})_{4}$. Rate constants were calculated using conventional and variational transition state theories for reactions in the first two pathways. The calculated rates are similar to the rates calculated for the

\footnotetext{
${ }^{*}$ Corresponding author

Email address: mk306@cam.ac.uk (Markus Kraft)
} 
corresponding isopropanol reactions, providing support for the analogy with isopropanol. The mechanism was used to simulate the ignition delay of isopropanol and TTIP. Excellent agreement was observed with experimental data for isopropanol. However, the mechanism over predicted the ignition delay for TTIP. The discrepancy was shown to be unlikely to be caused by the modest difference between the true reaction rates for the TTIP system and those assumed based on the analogy with isopropanol. It was found that the sensitivity of the TTIP decomposition to the presence of water must be caused by additional chemical pathways than the ones given by isopropanol analogy.

Keywords:

TTIP, titanium dioxide, nanoparticles, reaction mechanism, titanium tetraisopropoxide

\section{Introduction}

Titanium dioxide $\left(\mathrm{TiO}_{2}\right)$ particles have important applications in pigments, semiconductors, catalysis, electrochemical sensors and functionalised nanoparticles. The functional behaviour of the product is strongly influenced by the size, shape, morphology and crystalline phase of the particles.

The two main approaches used to manufacture $\mathrm{TiO}_{2}$ are flame aerosol synthesis and wet (liquid-phase) chemistry. Wet methods permit some control of the particle size, but the product may be amorphous and contain impurities [1]. Flame synthesis methods enable continuous operation and produce a high purity product [2].

The main precursors used in the flame synthesis of $\mathrm{TiO}_{2}$ are titanium 
tetrachloride $\left(\mathrm{TiCl}_{4}\right)$ and titanium tetraisopropoxide $\left(\mathrm{Ti}\left(\mathrm{OC}_{3} \mathrm{H}_{7}\right)_{4}\right.$, TTIP). $\mathrm{TiCl}_{4}$ is typically used for industrial processes. TTIP is less corrosive and easier to handle, so is often preferred for laboratory investigations. Various attempts have been made to understand the processes controlling the flame synthesis of $\mathrm{TiO}_{2}$ particles.

Compared to $\mathrm{TiCl}_{4}$ [see 3, 4, 5, 6, 7, 8, 9, and references therein], comparatively little is known about the reactions leading to the formation of $\mathrm{TiO}_{2}$ from TTIP. Okuyama et al. [10] studied the synthesis of $\mathrm{TiO}_{2}$ in a hot wall reactor. In this and subsequent studies [11, 12, 13] Okuyama and co-workers observed a first-order reaction rate for the thermal decomposition of TTIP. A correlation with the primary particle size, morphology and crystallinity of the resulting particles was noted for temperature, TTIP concentration and rate of reaction. This is in agreement with recent studies [14]. Fictorie et al. [15] conducted a mechanistic study of the chemical vapour deposition reactor of $\mathrm{TiO}_{2}$ from TTIP. This study and subsequent experiments by Ahn et al. [16] suggest two thermal decomposition pathways

$$
\begin{gathered}
\mathrm{Ti}\left(\mathrm{OC}_{3} \mathrm{H}_{7}\right)_{4} \stackrel{T>400^{\circ} \mathrm{C}}{\longrightarrow} \mathrm{TiO}_{2}+4 \mathrm{C}_{3} \mathrm{H}_{6}+2 \mathrm{H}_{2} \mathrm{O}, \\
\mathrm{Ti}\left(\mathrm{OC}_{3} \mathrm{H}_{7}\right)_{4} \stackrel{T<400^{\circ} \mathrm{C}}{\longrightarrow} \mathrm{TiO}_{2}+2 \mathrm{C}_{3} \mathrm{H}_{6}+2 \mathrm{C}_{3} \mathrm{H}_{7} \mathrm{OH} .
\end{gathered}
$$

Equation (11) was also suggested by Okuyama et al. [11, who proposed a thermal decomposition rate based on the kinetics of propylene formation. Hydrolysis reactions are another important pathway which must also be considered [12],

$$
\mathrm{Ti}\left(\mathrm{OC}_{3} \mathrm{H}_{7}\right)_{4}+2 \mathrm{H}_{2} \mathrm{O} \longrightarrow \mathrm{TiO}_{2}+4 \mathrm{C}_{3} \mathrm{H}_{7} \mathrm{OH} \text {. }
$$


Various authors have used TTIP-doped premixed flames to study the evolution of $\mathrm{TiO}_{2}$ particles. Yeh et al. [17] studied the factors influencing particle morphology and crystalline phase in a $\mathrm{CH}_{4} / \mathrm{O}_{2} / \mathrm{N}_{2}$ flame. A correlation of the crystal phase with residence time, flame temperature and TTIP concentration was observed. Similar results were reported by Ma and Yang [18, 19]. Arabi-Katbi et al. [20] used in situ Fourier transform infrared spectroscopy and transmission electron microscopy to analyse the particle processes in a $\mathrm{CH}_{4} / \mathrm{O}_{2} / \mathrm{N}_{2} / \mathrm{Ar}$ flame. They observed an increase in particle size along the flame, but limited aggregation. It was suggested that surface growth and sintering may be important particle processes. This is supported by Tsantilis et al. [21], who stress the role of surface growth.

A simple one-step process, either for thermal decomposition, hydrolysis or both is often assumed for the decomposition of TTIP [11, 21, 22, 23, 24]. To the best of our knowledge, the study of TTIP decomposition in a $\mathrm{H}_{2} / \mathrm{O}_{2} / \mathrm{Ar}$ flame by Shmakov et al. [25] is the only attempt at suggesting a more detailed mechanism. They propose a semi-empirical scheme containing 21 species and 25 reactions describing both hydrolysis and thermal decomposition. The scheme assumes that TTIP decomposes to form titanium hydroxide, $\mathrm{Ti}(\mathrm{OH})_{4}$, via the successive replacement of each isopropoxide branch $\left(-\mathrm{OC}_{3} \mathrm{H}_{7}\right)$ with a hydroxyl group $(-\mathrm{OH})$, followed by the decomposition of $\mathrm{Ti}(\mathrm{OH})_{4}$ to ultimately form $\mathrm{TiO}_{2}$.

It is desired to develop a comprehensive kinetic mechanism to describe the formation of $\mathrm{TiO}_{2}$ from TTIP. Providing that it contains all the important reaction pathways with appropriate kinetic and thermodynamic parameters, such a mechanism should be valid over a wide range of conditions and would 
facilitate theoretical investigations of the underlying physical and chemical processes. Buerger et al. [26] recently made a first step in this direction. They systematically proposed a set of candidate products that might be produced from the decomposition of TTIP. They calculated the electronic structure and thermodynamic properties of each species, and used an equilibrium analysis to identify the most thermodynamically stable species. $\mathrm{Ti}(\mathrm{OH})_{4}$ was shown to be the most stable species at temperatures below $1250 \mathrm{~K}$. $\mathrm{TiO}_{2}$ was unstable at all temperatures below $3000 \mathrm{~K}$.

The purpose of this paper is to propose a detailed chemical kinetic mechanism to describe the thermal decomposition of titanium tetraisopropoxide (TTIP). The final product in the proposed mechanism is titanium hydroxide $\left(\mathrm{Ti}(\mathrm{OH})_{4}\right)$, an essential intermediate decomposition product in the synthesis of titanium dioxide $\left(\mathrm{TiO}_{2}\right)$ particles. The reactions of $\mathrm{Ti}(\mathrm{OH})_{4}$ to form $\mathrm{TiO}_{2}$ particles require the consideration of particle processes and is beyond the scope of this study. This paper aims to present a systematic analysis of the possible reaction pathways, identify the most plausible species and reactions and assess the performance of the mechanism against experimental data. The thermodynamic data calculated by Buerger et al. 26] are used for Ti-containing species throughout. The data were calculated systematically using the same methodology and level of theory across all titanium species.

\section{Computational details}

\subsection{Mechanism generation}

Plausible elementary reactions must be identified in order to construct

a trialled mechanism to describe the thermal decomposition of TTIP. The 
manual derivation of a comprehensive mechanism along with ab initio calculation of the unknown rate constants is computationally intractable. Rather, we adopt a systematic approach similar to that of Nurkowski et al. [27, 28], where a mechanism to describe the decomposition of the ethoxy branches of tetraethoxysilane was developed based on an analogy with the decomposition of ethanol.

In this case, we draw an analogy between the decomposition of isopropanol $\left(\mathrm{iC}_{3} \mathrm{H}_{7} \mathrm{OH}\right)$ and the decomposition of the isopropoxide branches $\left(-\mathrm{OC}_{3} \mathrm{H}_{7}\right)$ of TTIP. It is believed that isopropanol may be a good candidate for this task because both isopropanol and the isopropoxide branches have similar structure and bond strengths as shown in Fig. 1. This suggests that the rate constants for the isopropanol reactions may be a reasonable first approximation for the rate constant of the corresponding TTIP reactions, enabling the creation of a TTIP mechanism that can be used as a starting point for further investigation.

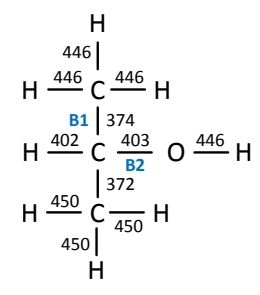

(a) $\mathrm{iC}_{3} \mathrm{H}_{7} \mathrm{OH}$

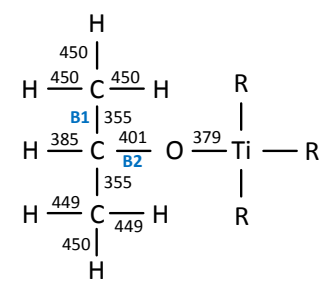

(b) TTIP

Figure 1: Bond strengths (in $\mathrm{kJ} / \mathrm{mol}$ ) calculated at the B97-1/6-311+G(d,p) level of theory.

A set of rules were developed to describe the decomposition of each $-\mathrm{OC}_{3} \mathrm{H}_{7}$ branch. The reaction rules, organised by the branch to be decom- 
posed, are described in Sections 2.1.1 to 2.1.9 and were applied recursively to suggest systematic permutations of species and reactions that could participate in the decomposition. Note that species with more than one radical site were rejected on the grounds that they were considered to be unstable and unlikely to be important. Likewise, reactions forming $\mathrm{C}=\mathrm{C}$ double bonds were considered, but reactions forming $\mathrm{C} \equiv \mathrm{C}$ triple bonds were not.

Initial estimates of the rate parameters were taken from the isopropanol mechanism proposed by Johnson et al. [29]. For the reaction rules where no rate parameters were available in Johnson's mechanism, other resources were considered. The resources are explicitly identified where they are used in sections 2.1.4, 2.1.7 and 2.1.9. All the proposed reactions are considered to be reversible. The reverse rates are calculated using chemical equilibrium, where the thermochemical data for each Ti-containing species are taken from Buerger et al. [26].

Several versions of the mechanism were generated.

- Mechanism 1 describes the thermal decomposition of TTIP via a direct analogy with the mechanism proposed by Johnson et al. [29] (rules 2.1.1] to 2.1.8.

- Mechanism 2 additionally includes representative hydrolysis reactions (rule 2.1.9).

- Mechanism 3 was used to explore the sensitivity of TTIP ignition delay simulations to various rate parameters.

All mechanisms and thermochemical data are provided as Supplementary material. 


\subsubsection{Reactions for $-\mathrm{OC}_{3} \mathrm{H}_{7}$}

Unimolecular decomposition reactions to produce $-\mathrm{OC}^{\cdot} \mathrm{HCH}_{3},-\mathrm{O}^{*}$ and $-\mathrm{OH}$ branches via $\mathrm{C}-\mathrm{C}$ and $\mathrm{C}-\mathrm{O}$ bond cleavage and a four-member ring transition state. The abstraction of primary and secondary hydrogens leading to the formation of $-\mathrm{OCH}\left(\mathrm{C}^{\cdot} \mathrm{H}_{2}\right)\left(\mathrm{CH}_{3}\right)$ and $-\mathrm{OC} \cdot\left(\mathrm{CH}_{3}\right)_{2}$ branches.

\subsubsection{Reactions for $-\mathrm{OC} \cdot\left(\mathrm{CH}_{3}\right)_{2}$}

Abstraction of atomic hydrogen from the primary carbon atom to produce $-\mathrm{OC}=\mathrm{CH}_{2}\left(\mathrm{CH}_{3}\right)$ branches.

\subsubsection{Reactions for $-\mathrm{OCH}\left(\mathrm{C}^{\cdot} \mathrm{H}_{2}\right)\left(\mathrm{CH}_{3}\right)$}

Unimolecular decomposition reactions to form $-\mathrm{O}^{*}$ and $-\mathrm{OCH}=\mathrm{CH}_{2}$ branches by releasing $\mathrm{C}_{3} \mathrm{H}_{6}$ and $\mathrm{C}^{\cdot} \mathrm{H}_{3}$.

\subsubsection{Reactions for $-\mathrm{OC}_{2} \mathrm{H}_{5}$}

Unimolecular decomposition reactions to form $-\mathrm{OC}^{\cdot} \mathrm{H}_{2},-\mathrm{O}^{\cdot}$ and $-\mathrm{OH}$ branches by releasing $\mathrm{C}^{\cdot} \mathrm{H}_{3}, \mathrm{C}_{2} \mathrm{H}_{5}$ and $\mathrm{C}_{2} \mathrm{H}_{4}$ via $\mathrm{C}-\mathrm{C}$ and $\mathrm{C}-\mathrm{O}$ bond cleavage and a four-member ring transition state. Abstraction of hydrogen to form $-\mathrm{OC} \cdot \mathrm{HCH}_{3}$ and $-\mathrm{OCH}_{2} \mathrm{C}^{\cdot} \mathrm{H}_{2}$. The transformation of $-\mathrm{OC}_{2} \mathrm{H}_{5}$ to $-\mathrm{OCH}=\mathrm{CH}_{2}$ based on the rate of $\mathrm{R} 4$ from Park et al. [30].

\subsubsection{Reactions for $-\mathrm{OC} \cdot \mathrm{H}_{2}$ and $-\mathrm{OCH}_{3}$}

The transformation between $-\mathrm{OC} \cdot \mathrm{H}_{2}$ and $-\mathrm{OCH}_{3}$ via hydrogen addition and hydrogen abstraction. Unimolecular decomposition of $-\mathrm{OCH}_{3}$ to release $\mathrm{C} \cdot \mathrm{H}_{3}$ and form $-\mathrm{O} \cdot$ branches. 


\subsubsection{Reactions for $-\mathrm{OC}=\mathrm{CH}_{2}\left(\mathrm{CH}_{3}\right)$ and $-\mathrm{OCH}=\mathrm{CH}_{2}$}

Unimolecular decomposition to form $-\mathrm{O}^{*}$ branches via the release of $\mathrm{C} \cdot=\mathrm{CH}_{2}\left(\mathrm{CH}_{3}\right)$ and $\mathrm{C} \cdot \mathrm{H}=\mathrm{CH}_{2}$.

\subsubsection{Reactions for $-\mathrm{OC} \cdot \mathrm{HCH}_{3}$ and $-\mathrm{OCH}_{2} \mathrm{C} \cdot \mathrm{H}_{2}$}

Hydrogen abstraction to form $-\mathrm{OCH}=\mathrm{CH}_{2}$. The rate for $-\mathrm{OCH}_{2} \mathrm{C}^{\cdot} \mathrm{H}_{2}$ is taken from the theoretical study of Rao et al. [31. The rate for $-\mathrm{OC} \cdot \mathrm{HCH}_{3}$ is taken from Johnson et al. [29]. The unimolecular decomposition of $-\mathrm{OCH}_{2} \mathrm{C}^{\cdot} \mathrm{H}_{2}$ to release $\mathrm{C}_{2} \mathrm{H}_{4}$ and form $-\mathrm{O}^{*}$ branches.

\subsubsection{Reactions for $-\mathrm{O}^{\circ}$ and $-\mathrm{OH}$}

The transformation between $-\mathrm{O}^{*}$ and $-\mathrm{OH}$ branches via hydrogen addition and abstraction.

\subsubsection{Hydrolysis reactions for $-\mathrm{OC}_{3} \mathrm{H}_{7}$}

The hydrolysis of TTIP, where water reacts with an $-\mathrm{OC}_{3} \mathrm{H}_{7}$ branch to form isopropanol and a $-\mathrm{OH}$ branch, was included in Mechanism 2. The corresponding reaction rate was taken from Shmakov et al. [25].

\subsection{Flux and sensitivity analysis}

Flux and sensitivity analyses were used to identify the most important species and reactions in the proposed mechanism. All calculations were performed using the kinetics ${ }^{\circledR}$ software package 32 .

The flux was calculated as the integrated flux of titanium in order to obtain a global overview of the behaviour of the mechanism. The integrated flux is defined as,

$$
F_{i, j, k}=V \sum_{r} \int_{0}^{\tau} \frac{n_{i, j} n_{i, k} \omega_{r}(t)}{N_{i, r}} \mathrm{~d} t \quad(\mathrm{~mol}),
$$


where $F_{i, j, k}$ is the integrated flux of element $i$ between species $j$ and $k, \tau$ is the simulation time, $V$ is the volume of the mixture, $n_{i, j}, n_{i, k}$ are the numbers of element $i$ in species $j$ and $k, N_{i, r}$ is the sum of atoms of element $i$ on either side of the reaction $r$ and $\omega_{r}(t)$ is the rate of reaction $r$.

The sensitivity was assessed using the maximum normalised sensitivity coefficients,

$$
S_{i, k}=\max _{t}\left\{\frac{A_{i}}{X_{k}(t)}\left(\frac{\partial X_{k}(t)}{\partial A_{i}}\right)\right\},
$$

where $A_{i}$ is a vector of model parameters and $X_{k}(t)$ is a dependent variable chosen as a measure of the model response. In this work, the pre-exponential factors of each reaction were taken as the model parameters and the concentration of hydroxyl radicals $\mathrm{OH}$ as the model response. The derivative $\partial X_{k}(t) / \partial A_{i}$ was estimated by a forward finite difference method with a $1 \%$ perturbation of the model parameters.

\subsection{Reaction rate parameter estimation}

The initial geometry and harmonic frequencies of reactants, products and transition states were calculated at the B97-1/6-311+G(d,p) level of theory. Higher level energies were estimated using the CBS-Q basis set extrapolation method [33, 34].

The rates of reactions with barriers were computed using conventional transition state theory (TST) and the microcanonical RRKM (Rice-RamspergerKassel-Markus) method [35, 36, 37] implemented in the Master Equation code [38]. Additionally, an Eckart tunnelling correction was included [39, 40]. Reaction rates for barrier-less channels were computed using a variable reaction coordinate transition state theory (VRC-TST) [41]. A detailed descrip- 
tion of this method can be found in many publications [42, 43, 44, 28] and is not repeated here.

The reaction coordinate in VRC-TST was defined in two different ways depending on the separation distances of the fragments. For short separations, 4-7.5 au, bond-length transition state dividing surfaces were used with a pair of pivot points fixed at the atoms at either end of the bond in question. For large separations, 8-20 au, a centre of mass (CoM) transition state dividing surfaces were used with a pair of pivot points fixed at the CoM of the fragments. Final calculations were performed at the energy, $E$, and angular momentum, $J$, resolved level where the rate coefficient was minimised by finding the optimal dividing surface for each $(E, J)$ pair (for energy equal to or less than $E$ and angular momentum quantum number equal to $J$ ). Optimisation of the surface was performed at evenly spaced grid points with a spacing of 0.5 and 2 au for small and large separations respectively.

The fragment-fragment interaction potential in the VRC-TST computations was obtained using CASPT2/cc-pVDZ level of theory [45, 46] with a two-electron, two-orbital active space. The internal structure of the fragments was fixed at their equilibrium geometries during the energy evaluations.

All electronic structure calculations used for TST were performed using Gaussian09 [47. The VRC-TST calculations were performed using MOLPRO [48]. 


\section{Results}

Several detailed mechanisms have been proposed to describe the decomposition of TTIP. Mechanism 1 contains 462 titania species in 8,666 reactions in addition to 237 species and 1415 reactions from the isopropanol mechanism proposed by Johnson et al. [29]. Mechanisms 2 and 3 contain an additional 182 hydrolysis reactions.

\subsection{Flux and sensitivity analysis}

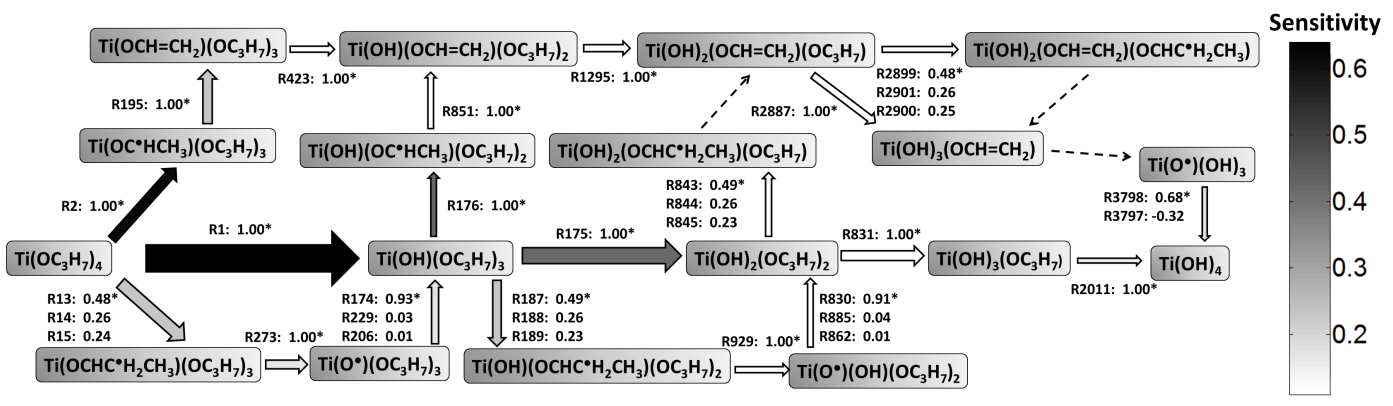

Figure 2: Main species and reaction pathways in the thermal decomposition of TTIP up to the point of ignition. The thickness of the arrows is proportional to the integrated flux of titanium. The normalised reaction-wise contributions to the flux are shown next to each arrow. Dashed arrows indicate a pathway that proceeds via several other species. The colour of each arrow indicates the normalised sensitivity of the $\mathrm{OH}$ radical concentration to the reaction indicated with an asterisk $\left(^{*}\right)$.

Figure 2 shows the main species and reaction pathways for simulations of the TTIP ignition delay in dry air using Mechanism 1. The reaction pathways and sensitivity are shown for an initial temperature of $1386 \mathrm{~K}$, but are consistent across the range 1200-1500 K. Note that the data in Fig. 2 are calculated up to the point of ignition. 
The main reaction pathways for the decomposition of the isopropoxide branches are the step-wise release of $\mathrm{C}_{3} \mathrm{H}_{6}$ via four-member ring transition states (the main horizontal pathway in Fig. 2), the successive abstraction of $\mathrm{CH}_{3}$ radicals via $\mathrm{C}-\mathrm{C}$ bond cleavage followed by hydrogen abstraction to form $\mathrm{C}=\mathrm{C}$ double bonds (the upwards pathways in Fig. 2), and hydrogen abstraction from the isopropoxide methyl groups followed by the release of $\mathrm{C}_{3} \mathrm{H}_{6}$ (the downwards pathways in Fig. 22). The final decomposition product is $\operatorname{Ti}(\mathrm{OH})_{4}$. This is consistent with Buerger et al. [26], where $\operatorname{Ti}(\mathrm{OH})_{4}$ was the most stable titanium species for temperatures less than $1250 \mathrm{~K}$. The thermodynamic stability gradually decreases above $1250 \mathrm{~K}$ and titanium species smaller than $\mathrm{Ti}(\mathrm{OH})_{4}$ become thermodynamically more stable. The step-wise release of $\mathrm{C}_{3} \mathrm{H}_{6}$ is consistent with the thermal decomposition (as opposed to hydrolysis) scheme proposed by Shmakov et al. [25].

The reactions in the main reaction pathways show high sensitivity. Within each pathway, the most sensitive reactions are those at the beginning of the pathway. The rates of the $\mathrm{C}_{3} \mathrm{H}_{6}$ release and $\mathrm{CH}_{3}$ abstraction pathways are studied in more detail.

\subsection{Reaction rate parameter estimation}

The rates of $\mathrm{C}_{3} \mathrm{H}_{6}$ release from an isopropoxide branch (channel 1) and of $\mathrm{CH}_{3}$ abstraction via $\mathrm{C}-\mathrm{C}$ bond cleavage (channel 2) were calculated. In order to minimise computational errors, the rates were not calculated for TTIP, but titanium isopropoxide, $\mathrm{Ti}(\mathrm{OH})_{3}\left(\mathrm{OC}_{3} \mathrm{H}_{7}\right)$, (TIP). This is the smallest titania species able to undergo these reactions. The rates of the analogous isopropanol reactions were computed at the same level of theory for the purpose of comparison. 
Figure 3 a shows the calculated high-pressure limited rate constants for channel (1) in TIP and isopropanol, $k_{1 T}^{\infty}$ and $k_{1 i}^{\infty}$. The calculated rates show good agreement (within a factor of 1.8) with data reported in literature [29, 49, 50]. The TIP and isopropanol rate coefficients are similar (within a factor of 5) for temperatures greater than $800 \mathrm{~K}$. The TIP rate is 10-20 times faster at temperatures below this.

Figure $3 \mathrm{~b}$ shows the calculated high-pressure limited rate constants for channel (2) in TIP and isopropanol, $k_{2 T}^{\infty}$ and $k_{2 i}^{\infty}$. Data from Johnson et al. [29] is included for comparison. The calculated isopropanol rate is in excellent agreement (within a factor of 1.2). The TIP and isopropanol rates are very similar (within a factor of 2).

The calculated rates support the analogy with isopropanol. However, it must also be stressed that there remains scope to refine the estimates of the rate constants for these reactions in addition to estimating rates for the other reaction channels.

\subsection{Ignition delay calculations}

The performance of the proposed mechanisms is assessed against measurements of the ignition delay for isopropanol [29] and TTIP [51]. All sim-

ulations were performed using the kinetics ${ }^{\circledR}$ software package [32]. Note that TTIP data that are suitable to assess the performance of the proposed gas-phase chemistry is scarce. In particular, data from studies that form $\mathrm{TiO}_{2}$ particles are assumed to be unsuitable because of the strong effect of the surface reactions [see for example 13, 21].

Figure 4(a) shows that the mechanisms accurately reproduce experimental measurements of the ignition delay for isopropanol. This confirms that 


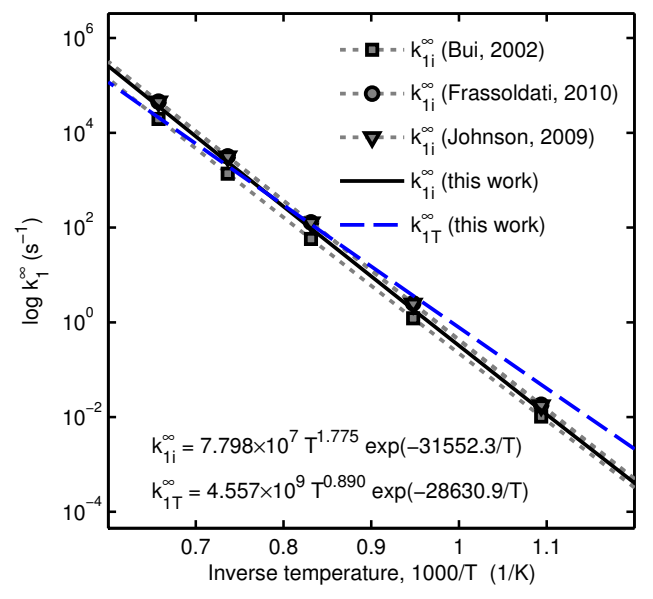

(a) Unimolecular decomposition (1)

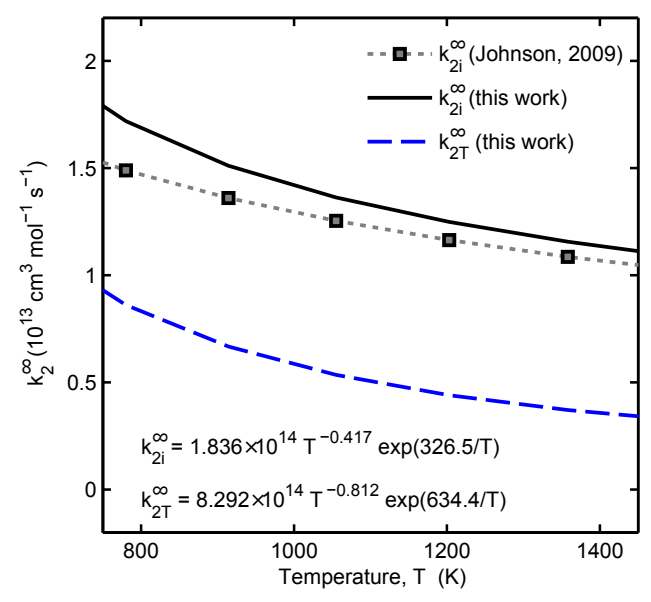

(b) $\mathrm{C}-\mathrm{C}$ bond cleavage (2)

Figure 3: Theoretical predictions for the high-pressure decomposition (a) and association (b) rate constants. Rate coefficients $k_{1 i}^{\infty}$ and $k_{2 i}^{\infty}$ depict data for isopropanol whereas $k_{1 T}^{\infty}$ and $k_{2 T}^{\infty}$ present data for $\mathrm{Ti}(\mathrm{OH})_{3}\left(\mathrm{OC}_{3} \mathrm{H}_{7}\right)$.

the TTIP reactions have not had any unintended effect on the underlying hydrocarbon chemistry.

Figure $4(\mathrm{~b})$ presents a comparison of various TTIP ignition delay simulations versus experimental data from Abdali et al. [51]. The ignition delay was measured in synthetic dry air at 1.7 bar with 2000 ppm of TTIP. It was additionally observed that TTIP decomposed too rapidly to allow measurements in the presence of water.

Mechanisms 1 and 2 both significantly over predict the ignition delay of TTIP. This is not necessarily unexpected given that (i) the TTIP rate parameters are taken by direct analogy from the corresponding isopropanol reactions and that (ii) Figs. 4(a) and (b), although not directly comparable, suggest that TTIP may decompose more rapidly than isopropanol. Note 
that the only water present in these simulations is that created by the decomposition of TTIP. The sensitivity of the ignition delay simulations to the used thermochemical data was stress tested by simulating the ignition delay using both reversible and irreversible reactions. The effect on the simulated ignition delay was negligible.

Mechanism 2 predicts a slight decrease in the ignition delay at low temperatures in the presence of wet air. This is expected in the sense that the relative rate of hydrolysis versus thermal decomposition is believed to increase at lower temperatures [12]. However, the size of the decrease falls a long way short of expectations based on the observation that the ignition

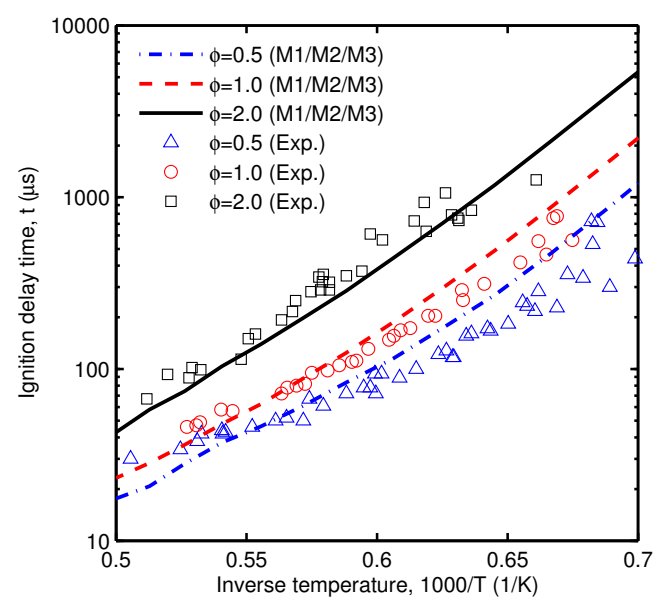

(a) Isopropanol. Experimental data from Johnson et al. [29. The experimental and simulated ignition delays were determined using the maximum $\mathrm{CH}$ radical concentration.

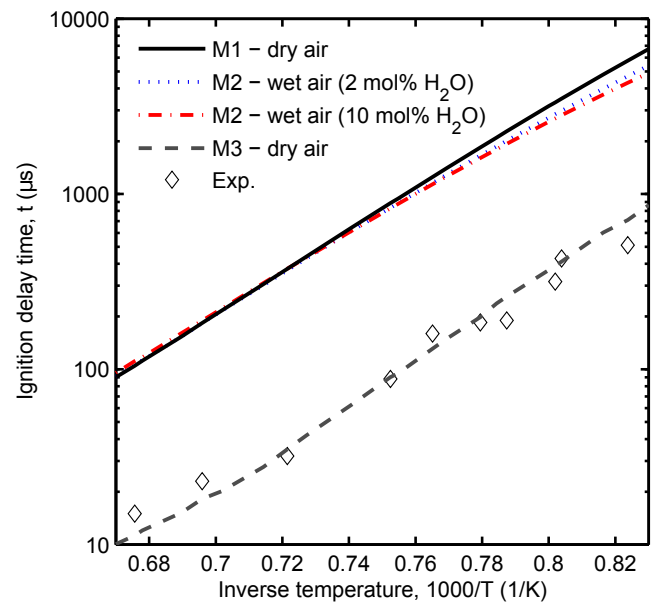

(b) TTIP. Experimental data from Abdali et al. [51. The experimental and simulated ignition delays were determined using the maximum $\mathrm{OH}$ radical concentration.

Figure 4: Ignition delay simulations. 
delay was too rapid to measure in the presence of water [51].

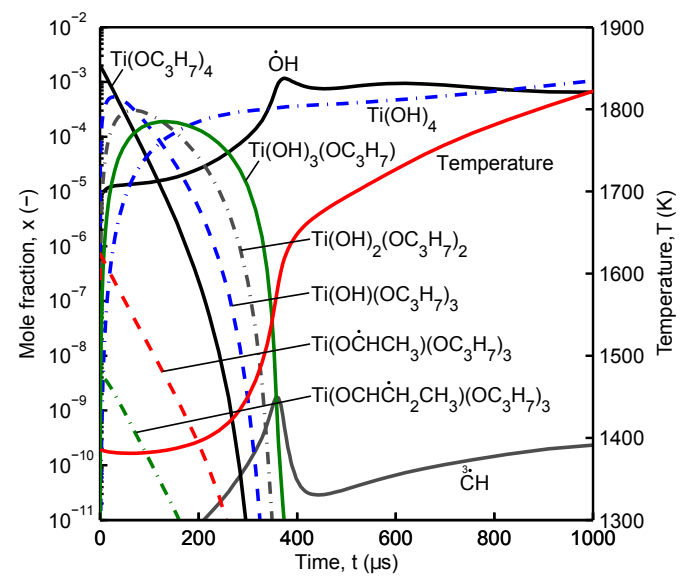

Figure 5: Temperature and key species profiles in a simulation of TTIP ignition using Mechanism 1 in dry air.

Figure 5 shows the evolution of the temperature and key species during the simulation of TTIP ignition as per Fig. 4|(b) (M1, dry air, $T_{\text {initial }}$ $=1386 \mathrm{~K}$ ). The concentration of TTIP is observed to decrease rapidly, followed by a sequence of peaks for $\mathrm{Ti}(\mathrm{OH})\left(\mathrm{OC}_{3} \mathrm{H}_{7}\right)_{3}, \mathrm{Ti}(\mathrm{OH})_{2}\left(\mathrm{OC}_{3} \mathrm{H}_{7}\right)_{2}$ and $\mathrm{Ti}(\mathrm{OH})_{3}\left(\mathrm{OC}_{3} \mathrm{H}_{7}\right)$ as the reaction proceeds along the main (horizontal) pathway in Fig. 2. The consumption of $\mathrm{Ti}(\mathrm{OH})_{3}\left(\mathrm{OC}_{3} \mathrm{H}_{7}\right)$ coincides with the maximum $\mathrm{OH}$ and $\mathrm{CH}$ radical concentrations and the maximum rate of temperature increase. These are all common metrics for detecting ignition events and imply that estimated value of the ignition delay will be insensitive to the choice of metric. Peaks corresponding to the other pathways in Fig. 2 are also observed, showing the rapid production and then consumption of $\mathrm{Ti}\left(\mathrm{OC} \cdot \mathrm{HCH}_{3}\right)\left(\mathrm{OC}_{3} \mathrm{H}_{7}\right)_{3}$ (upwards pathway in Fig. 2) and $\mathrm{Ti}\left(\mathrm{OCHC} \cdot \mathrm{H}_{2} \mathrm{CH}_{3}\right)\left(\mathrm{OC}_{3} \mathrm{H}_{7}\right)_{3}$ (downwards pathway in Fig. 2). Both are at lower concentrations than the species generated by the release of $\mathrm{C}_{3} \mathrm{H}_{6}$ along 
the main pathway.

The rates of the reactions identified in Fig. 2 were modified in order to check what magnitude of change might be required to explain the observed discrepancy in the ignition delay data. It was found that a 1000-fold increase in the rates of the $\mathrm{CH}_{3}$ radical abstraction reactions (R2, R176 etc. in Fig. 2) was required in order to achieve any form of agreement. This is shown as Mechanism 3 in Fig. 4(b). This level of agreement could not be achieved in either dry or wet air by modification of the rates of the step-wise release of $\mathrm{C}_{3} \mathrm{H}_{6}$ (R1, R175 etc. in Fig. 2), the hydrogen abstraction reactions (R13-15, R187-189 etc. in Fig. 2) or hydrolysis reactions included in Mechanism 2 via rule 2.1.9.

Whilst it was not feasible to check all possible modifications, and whilst it is still desirable to obtain accurate estimates of the rate parameters, the above observations suggest that the differences between TTIP and the corresponding isopropanol rates are unlikely to be responsible for the discrepancy observed in Fig. 4|(b), Rather, it is suggested that consideration should be given as to whether there are important pathways in addition to those suggested by the analogy with isopropanol. For example, reactions leading to the consumption of $\mathrm{TiOH}_{4}$ and/or hydrolysis pathways that are able to explain the observed sensitivity of the TTIP ignition delay to the presence of water. At this stage, these remain open questions for future research.

\section{Conclusions}

This paper presents a first attempt to derive a detailed and thermodynamically consistent chemical mechanism for the thermal decomposition of 
titanium tetraisopropoxide (TTIP). The mechanism is developed by analogy with the thermal decomposition of isopropanol described by Johnson et al. [29]. This approach is motivated by the observation that isopropanol and the isopropoxide branches of TTIP have a similar chemical structure and similar bond strengths.

The thermodynamic data for all titanium containing species in the proposed mechanism are taken from previous calculations [26]. The mechanism assumes that all reactions are reversible, where the reverse reaction rates are calculated using chemical equilibrium. Three versions of the mechanism were produced. Mechanism 1, describes the thermal decomposition of TTIP based on a strict analogy with Johnson et al. [29]. Mechanism 2 additionally contains some hydrolysis reactions which are expected to be important at low temperatures. Mechanism 3 was used to explore the sensitivity of TTIP ignition delay simulations to various rate parameters.

Flux and sensitivity analyses were used to identify the main intermediate species and most plausible reaction pathways for the thermal decomposition of TTIP. Three main pathways were observed. The step-wise release of $\mathrm{C}_{3} \mathrm{H}_{6}$, the successive abstraction of $\mathrm{CH}_{3}$ radicals followed by hydrogen abstraction to form $\mathrm{C}=\mathrm{C}$ double bonds, and hydrogen abstraction from the isopropoxide methyl groups followed by the release of $\mathrm{C}_{3} \mathrm{H}_{6}$. The final decomposition product is $\operatorname{Ti}(\mathrm{OH})_{4}$ in the current mechanism. This is a consequence of the analogy with isopropanol, where each $-\mathrm{OC}_{3} \mathrm{H}_{7}$ decomposes to ultimately form an $-\mathrm{OH}$ branch.

Electronic structure calculations were performed to check the level of similarity between the rates of the main TTIP decomposition and corresponding 
isopropanol reactions. It was shown that the TIP reaction for the release of $\mathrm{C}_{3} \mathrm{H}_{6}$ had a lower energy barrier, resulting in a slightly faster reaction rate, than for the corresponding isopropanol reaction. Likewise, a representative reaction for the abstraction of $\mathrm{CH}_{3}$ was shown to be slightly slower for the TTIP system than for isopropanol. The level of similarity provides support for using the isopropanol rates as a first estimate of the corresponding TTIP rates.

The mechanisms were used to simulate the ignition delay of TTIP. The current mechanisms over predict the experimentally observed ignition delay in dry air and did not show the expected sensitivity to the presence of water. Consideration of the types of changes required to achieve agreement with the experimental data suggest that these discrepancies are unlikely to be due to the level of uncertainty in the current kinetic parameters, most of which are taken by direct analogy with isopropanol.

There remain a number of open questions where further work is required. Firstly and most importantly, consideration should be given as to whether there are important pathways missing from the current mechanism. In particular, reactions leading to the consumption of $\mathrm{Ti}(\mathrm{OH})_{4}$ and/or hydrolysis pathways that are able to explain the observed sensitivity of the TTIP ignition delay to the presence of water. Secondly, it would be instructive to replace the isopropanol-based rate constants for the reactions along the main reaction pathways with calculated values and to confirm what impact, if any, this has on the agreement with the predicted and experimentally observed ignition delay times. 


\section{Acknowledgments}

This project is partly funded by the National Research Foundation (NRF), Prime Ministers Office, Singapore under its Campus for Research Excellence and Technological Enterprise (CREATE) programme. The authors thank Huntsman Pigments for financial support.

\section{References}

[1] B. Zhao, K. Uchikawa, H. Wang, Proc. Combust. Inst. 31 (2007) 851860.

[2] S. E. Pratsinis, Prog. Energy Combust. Sci. 24 (1998) 197-219.

[3] R. H. West, G. J. O. Beran, W. H. Green, M. Kraft, J. Phys. Chem. A 111 (2007) 3560-3565.

[4] R. H. West, M. S. Celnik, O. R. Inderwildi, M. Kraft, G. J. O. Beran, W. H. Green, Ind. Eng. Chem. Res. 46 (2007) 6147-6156.

[5] R. H. West, R. A. Shirley, M. Kraft, C. F. Goldsmith, W. H. Green, Combust. Flame 156 (2009) 1764-1770.

[6] R. Shirley, Y. Liu, T. S. Totton, R. H. West, M. Kraft, J. Phys. Chem. A 113 (2009) 13790-13796.

[7] T. S. Totton, R. Shirley, M. Kraft, Proc. Combust. Inst. 33 (2011) 493500 .

[8] J. Akroyd, A. J. Smith, R. Shirley, L. R. McGlashan, M. Kraft, Chem. Eng. Sci. 66 (2011) 3792-3805. 
[9] R. Shirley, J. Akroyd, L. A. Miller, O. R. Inderwildi, U. Riedel, M. Kraft, Combust. Flame 158 (2011) 1868-1876.

[10] K. Okuyama, Y. Kousaka, N. Tohge, S. Yamamoto, J. J. Wu, R. C. Flagan, J. H. Seinfeld, Amer. Inst. Chem. Engrs. 32 (1986) 2010-2019.

[11] K. Okuyama, R. Ushio, Y. Kousaka, R. C. Flagan, J. H. Seinfeld, Amer. Inst. Chem. Engrs. 36 (1990) 409-419.

[12] T. Seto, M. Shimada, K. Okuyama, Aerosol Sci. Technol. 23 (1995) $183-200$.

[13] K. Nakaso, K. Okuyama, M. Shimada, S. E. Pratsinis, Chem. Eng. Sci. 58 (2003) 3327-3335.

[14] Y. Wang, P. Liu, J. Fang, W.-N. Wang, P. Biswas, J. Nanopart. Res. 17 (2015).

[15] C. P. Fictorie, J. F. Evans, W. L. Gladfelter, J. Vac. Sci. Technol., A 12 (1994) 1108-1113.

[16] K.-H. Ahn, Y.-B. Park, D.-W. Park, Surf. Coat. Technol. 171 (2002) $198-204$.

[17] C. L. Yeh, S. H. Yeh, H. K. Ma, Powder Technol. 145 (2004) 1-9.

[18] H.-K. Ma, H.-A. Yang, J. Alloys Compd. 504 (2010) 115-122.

[19] H.-K. Ma, H.-A. Yang, J. Therm. Sci. 19 (2010) 567-575.

[20] O. I. Arabi-Katbi, S. E. Pratsinis, P. W. Morrison Jr., C. M. Megaridis, Combust. Flame 124 (2001) 560-572. 
[21] S. Tsantilis, H. K. Kammler, S. E. Pratsinis, Chem. Eng. Sci. 57 (2002) 2139-2156.

[22] N. Baguer, E. Neyts, S. Van Gils, A. Bogaerts, Chem. Vap. Deposition 14 (2008) 339-346.

[23] A. Modak, K. Puduppakkam, C. Naik, E. Meeks, in: Symposium YCombustion Synthesis of Functional Nanomaterials, volume 1506 of MRS Online Proceedings Library. doi:10.1557/opl.2013.1049.

[24] H.-K. Ma, T.-J. Pan, P.-T. Cheng, Aerosol Air Qual. Res. 14 (2014) $251-259$.

[25] A. G. Shmakov, O. P. Korobeinichev, D. A. Knyazkov, A. A. Paletsky, R. A. Maksutov, I. E. Gerasimov, T. A. Bolshova, V. G. Kiselev, N. P. Gritsan, Proc. Combust. Inst. 34 (2013) 1143-1149.

[26] P. Buerger, D. Nurkowski, J. Akroyd, S. Mosbach, M. Kraft, J. Phys. Chem. A 119 (2015) 8376-8387.

[27] D. Nurkowski, P. Buerger, J. Akroyd, M. Kraft, Proc. Combust. Inst. 35 (2015) 2291-2298.

[28] D. Nurkowski, S. J. Klippenstein, Y. Georgievskii, M. Verdicchio, A. W. Jasper, J. Akroyd, S. Mosbach, M. Kraft, Z. Phys. Chem. 229 (2015) 691-708.

[29] M. V. Johnson, S. S. Goldsborough, Z. Serinyel, P. O'Toole, E. Larkin, G. O'Malley, H. J. Curran, Energy Fuels 23 (2009) 5886-5898. 
[30] J. Park, R. S. Zhu, M. C. Lin, J. Chem. Phys. 117 (2002).

[31] H.-B. Rao, X.-Y. Zeng, H. He, Z.-R. Li, J. Phys. Chem. A 115 (2011) 1602-1608.

[32] CMCL Innovations, Kinetics v8.4.0, 2015. URL: http://www. cmclinnovations.com/.

[33] J. A. Montgomery, M. J. Frisch, J. W. Ochterski, G. A. Petersson, J. Chem. Phys. 110 (1999) 2822-2827.

[34] J. W. Ochterski, G. A. Petersson, J. A. Montgomery, J. Chem. Phys. 104 (1996) 2598-2619.

[35] O. K. Rice, H. C. Ramsperger, J. Am. Chem. Soc. 49 (1927) 1617-1629.

[36] L. S. Kassel, J. Phys. Chem. 32 (1928) 1065-1079.

[37] R. A. Marcus, Laser Chem. 2 (1983) 203-217.

[38] Y. Georgievskii, J. A. Miller, M. P. Burke, S. J. Klippenstein, J. Phys. Chem. A 117 (2013) 12146-12154.

[39] C. Eckart, Phys. Rev. 36 (1930) 878-892.

[40] H. S. Johnston, J. Heicklen, J. Phys. Chem. 66 (1962) 532-533.

[41] Y. Georgievskii, S. J. Klippenstein, J. Phys. Chem. A 110 (2006) 10528 10544.

[42] S. J. Klippenstein, J. Chem. Phys. 94 (1991) 6469-6482.

[43] S. J. Klippenstein, J. Chem. Phys. 96 (1992) 367-371. 
[44] S. J. Klippenstein, J. Phys. Chem. 98 (1994) 11459-11464.

[45] K. Andersson, P. Å. Malmqvist, B. O. Roos, J. Chem. Phys. 96 (1992) $1218-1226$.

[46] T. H. Dunning, J. Chem. Phys. 90 (1989) 1007-1023.

[47] M. J. Frisch, G. W. Trucks, H. B. Schlegel, G. E. Scuseria, M. A. Robb, et al., Gaussian 09 Revision D.01, 2009.

[48] H.-J. Werner, P. J. Knowles, G. Knizia, F. R. Manby, M. Schütz, et al., Molpro, version 2012.1, a package of ab initio programs, 2012. See, http://www.molpro.net.

[49] A. Frassoldati, A. Cuoci, T. Faravelli, U. Niemann, E. Ranzi, R. Seiser, K. Seshadri, Combust. Flame 157 (2010) 2-16.

[50] B. H. Bui, R. S. Zhu, M. C. Lin, J. Chem. Phys. 117 (2002) 11188-11195.

[51] A. Abdali, M. Fikri, H. Orthner, H. Wiggers, C. Schulz, Chem. Phys. Lett. 601 (2014) 54-58. 


\section{List of Tables}

\section{List of Figures}

$1 \quad$ Bond strengths for isopropanol and TTIP. . . . . . . . . . . 6

$2 \quad$ Main species and reaction pathways. . . . . . . . . . . . . . 12

3 Rate constants results . . . . . . . . . . . . . . . . 14

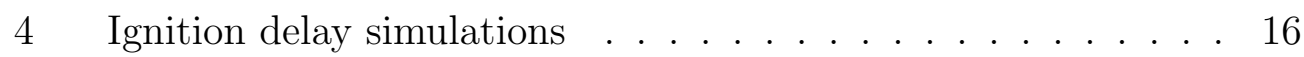

5 Temperature and key species profiles. . . . . . . . . . . . . . . 17

\section{List of Supplemental Material}

- Mechanism 1 file, 'Mechanism_1.txt'.

- Mechanism 2 file, 'Mechanism_2.txt'.

- Mechanism 3 file, 'Mechanism_3.txt'.

- Thermodynamic data file, 'ThermoData.txt'. 